\title{
Endodontically Treated Maxillary Premolars Restored with Glass Fiber Post under All Ceramic Crown
}

\author{
Ameni Adli'; ${ }^{1}$ Yosra Gassara²; N. Daouahi' ${ }^{1}$; Zohra Nouira ${ }^{3}$ \\ ${ }^{1}$ Associate Professor, Department of Fixed Prosthodontics, Academic Dental Clinic of Monastir \\ ${ }^{2}$ Assistant Professor, Department of Fixed Prosthodontics, Academic Dental Clinic of Monastir \\ ${ }^{3}$ Professor, Department of Fixed Prosthodontics, Academic Dental Clinic of Monastir
}

Corresponding Author: Ameni Adli

\begin{abstract}
Glass fiber posts and core are increasingly used in order to restore severely damaged endodontically treated teeth and particularly maxillary premolars that are prone to fracture. Their low modulus of elasticity which is similar to that of dentin allows the post to absorb stress and prevent root fracture. In addition, the glass fiber posts provide a natural hue by integrally bonding to the composite, thereby improving the aesthetics without compromising much on the strength.

Various factors are involved in the longevity of such treatment option, remaining tooth structure seems to be the most important.
\end{abstract}

Keywords: glass fiber posts, premolars, endodontically treated teeth, composite resin, fracture resistance, crown, ferrule, failure

\section{INTRODUCTION}

For many years the restoration of endodontically treated teeth (ETT) with extensive loss of coronal tooth structure consisted in stereotyped procedures systematically using post and core followed by the cementation of a full crown. Frequent longitudinal root fractures were observed because of their high elasticity modulus.

Recently, clinicians are increasingly opting for fiber post materials that have biomechanical characteristics similar to those of dentin. The main objective of this paper is to discuss the various factors involved in the longevity of maxillary premolars when restored with glass fiber post (GFPs) under all ceramic crown.

\section{CASE PRESENTATION}

A 26-year-old patient consult with a main chief complaint the restoration of the upper left second premolar (Figure 1). The tooth is discolored with a large composite filling and the periapical radiograph shows a good root canal treatment.

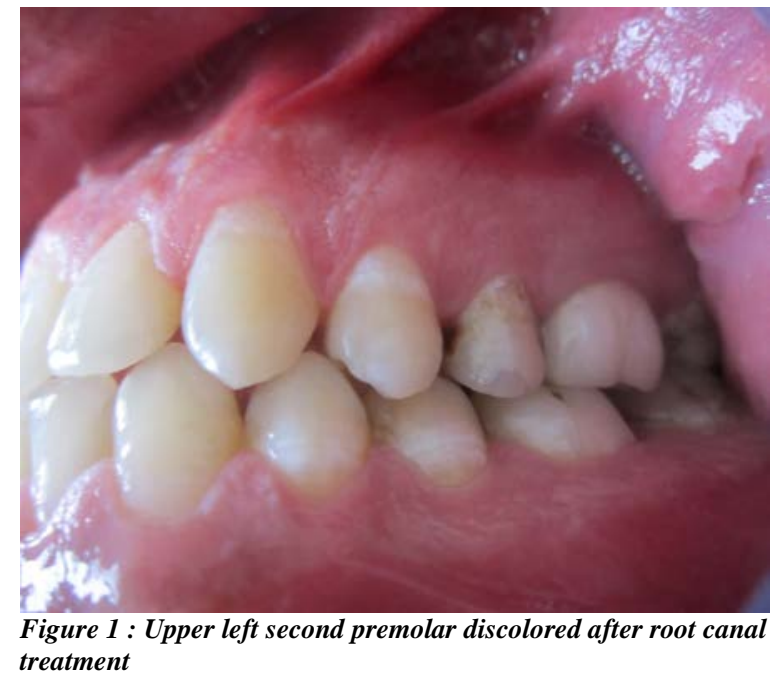

\section{Step by step treatment:}

After tooth preparation caries and an extended composite filling still to be 

crown.

removed (Figure 2). As a result, only the buccal wall still sound as well as $1 / 3$ of each other walls. In view of the significant tissue loss, a glass fiber post and core followed by a zirconia crown is indicated to meet the high aesthetic requirements of the patient.

First, post selection (Rely X Fiber Post No.2, 3M ESPE) is done according to the retroalveolar $\mathrm{x}$-ray (Figure 3), root canal preparation is done with the corresponding drill (figure 4) and retaining an apical seal of $4 \mathrm{~mm}$.

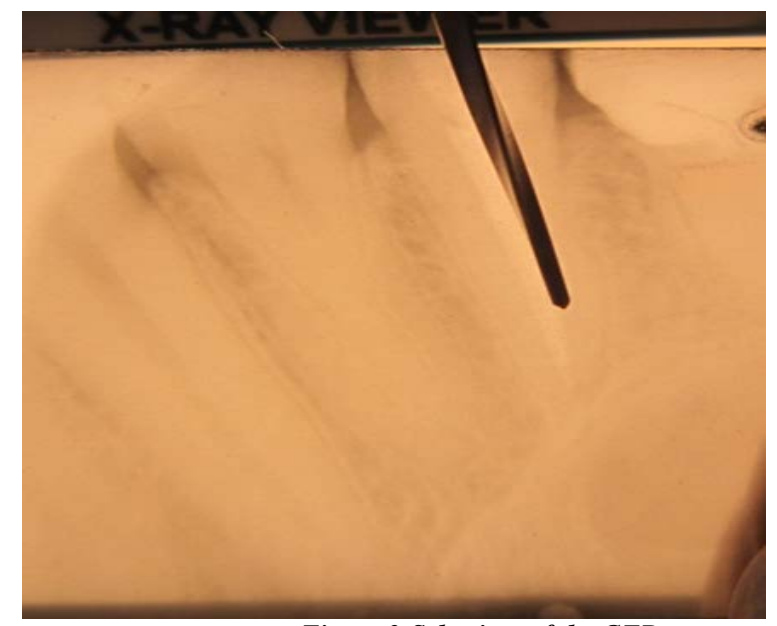

Figure 3:Selection of the GFP

Using a diamond disc the post is cut in such a way that its occlusal end is located $2 \mathrm{~mm}$ from the occlusion plane (Figure 5) then it is tried on in the post space to verify its passive insertion (Figure 6).

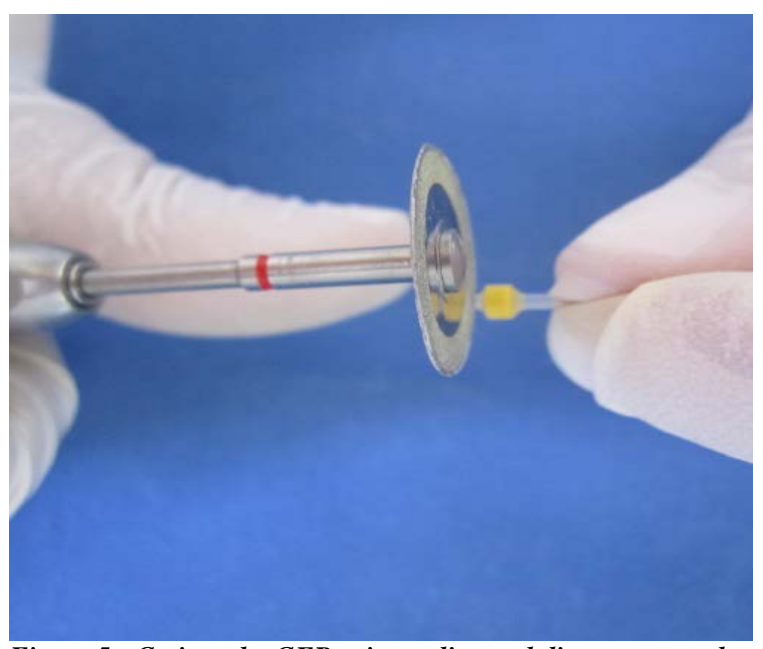

Figure 5 : Cuting the GFP using a diamond disc so to not alter the fibers

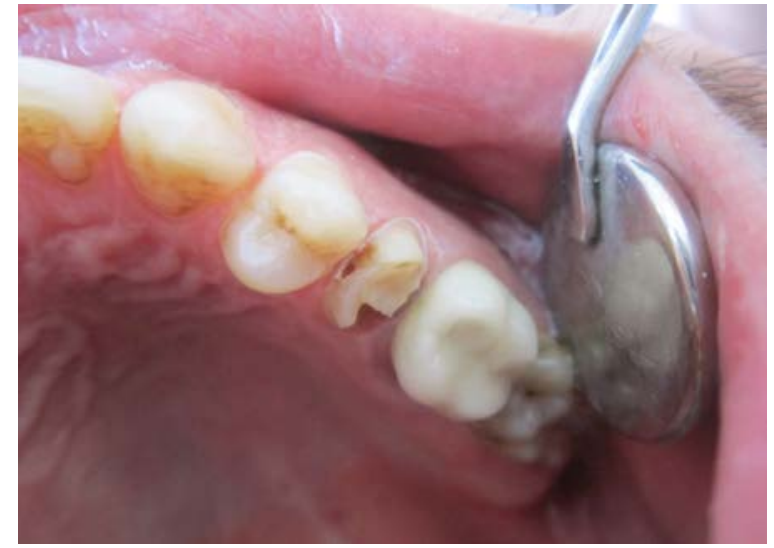

Figure 2: After tooth preparation caries and an extended composite filling still to be removed

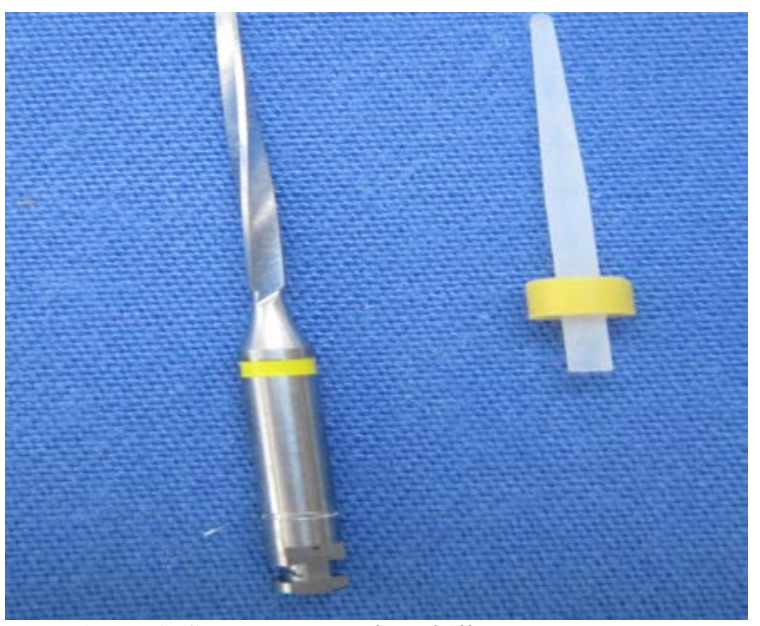

Figure 4: GFP+corresponding drill

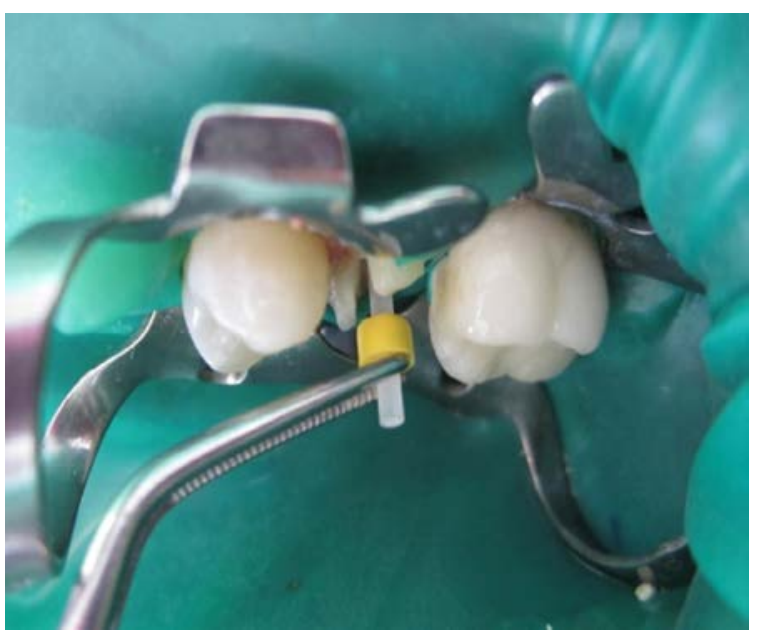

Figure 6: The post is tried on in the post space to verify its passive insertion

Second, the post is cleaned with ethanol and the canal is disinfected with a sodium hypochlorite solution. Rubber dam is placed in order to prevent moisture after what the post is cemented with RelyX $\mathrm{X}^{\mathrm{TM}}$ Unicem (3M ESPE, USA). The thin tip allows the composite to be brought back to 

crown.

the bottom of the canal and to avoid air bubbles (Figure 7,8, 9). The post is inserted slowly, making a slight withdrawal before placing it. The coronal part is restored with the same composite (Figures 10,11).

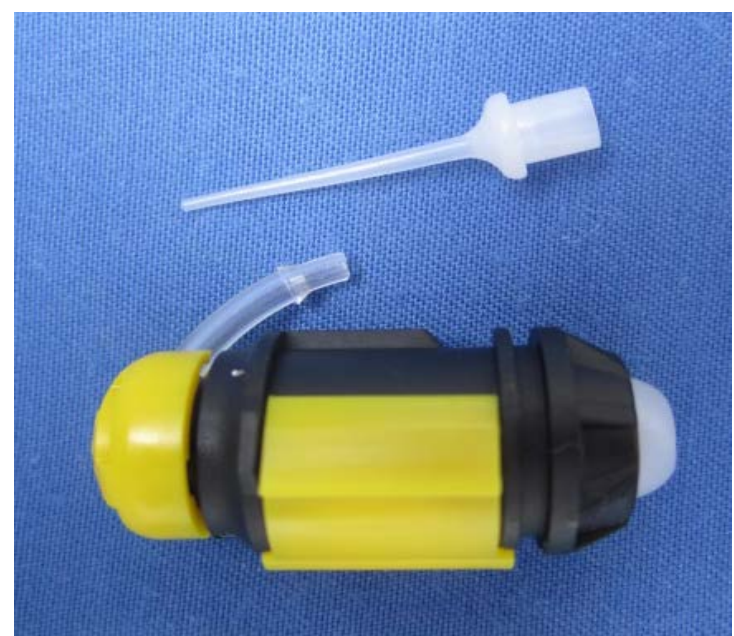

Figure 7: The thin tip allows the composite to be brought back to the bottom of the canal and to avoid air bubbles.

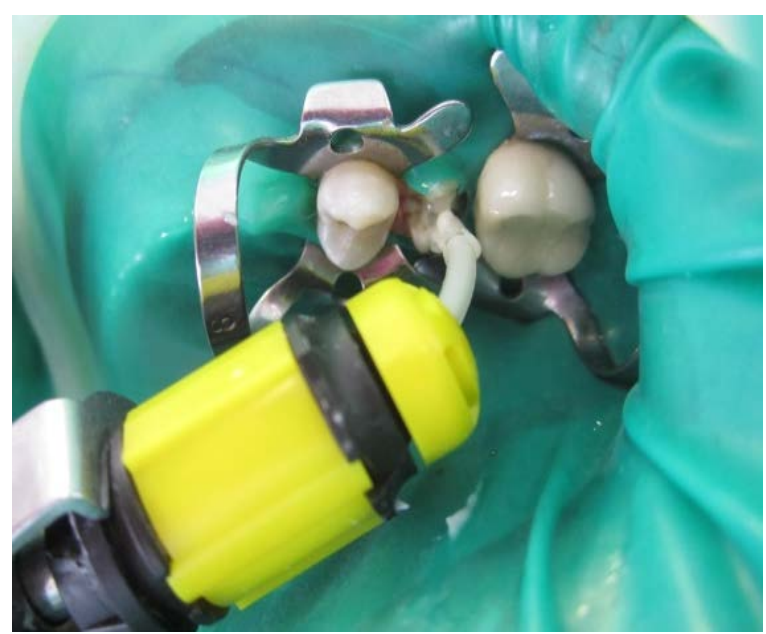

Figure 8 :GFP bonding

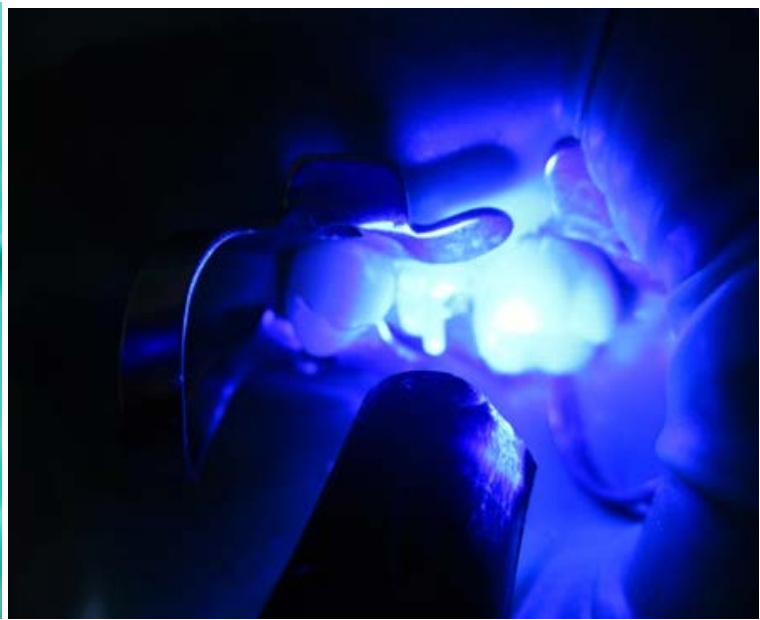

Figure 8 :Lightcuring

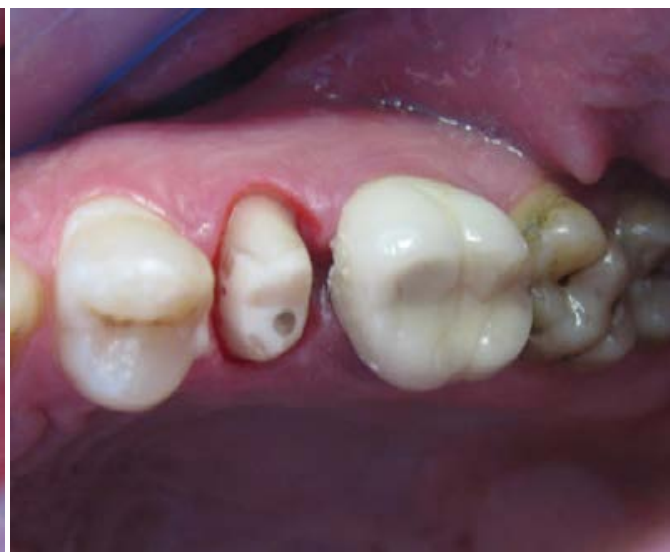

Figure 10,11: Clinical views after Glass fiber post and core
The final result is satisfactory thanks to the aesthetic properties of the layering ceramic and the power of light transmission of the (GFP) and composite (Figures $12,13,14$ ). 


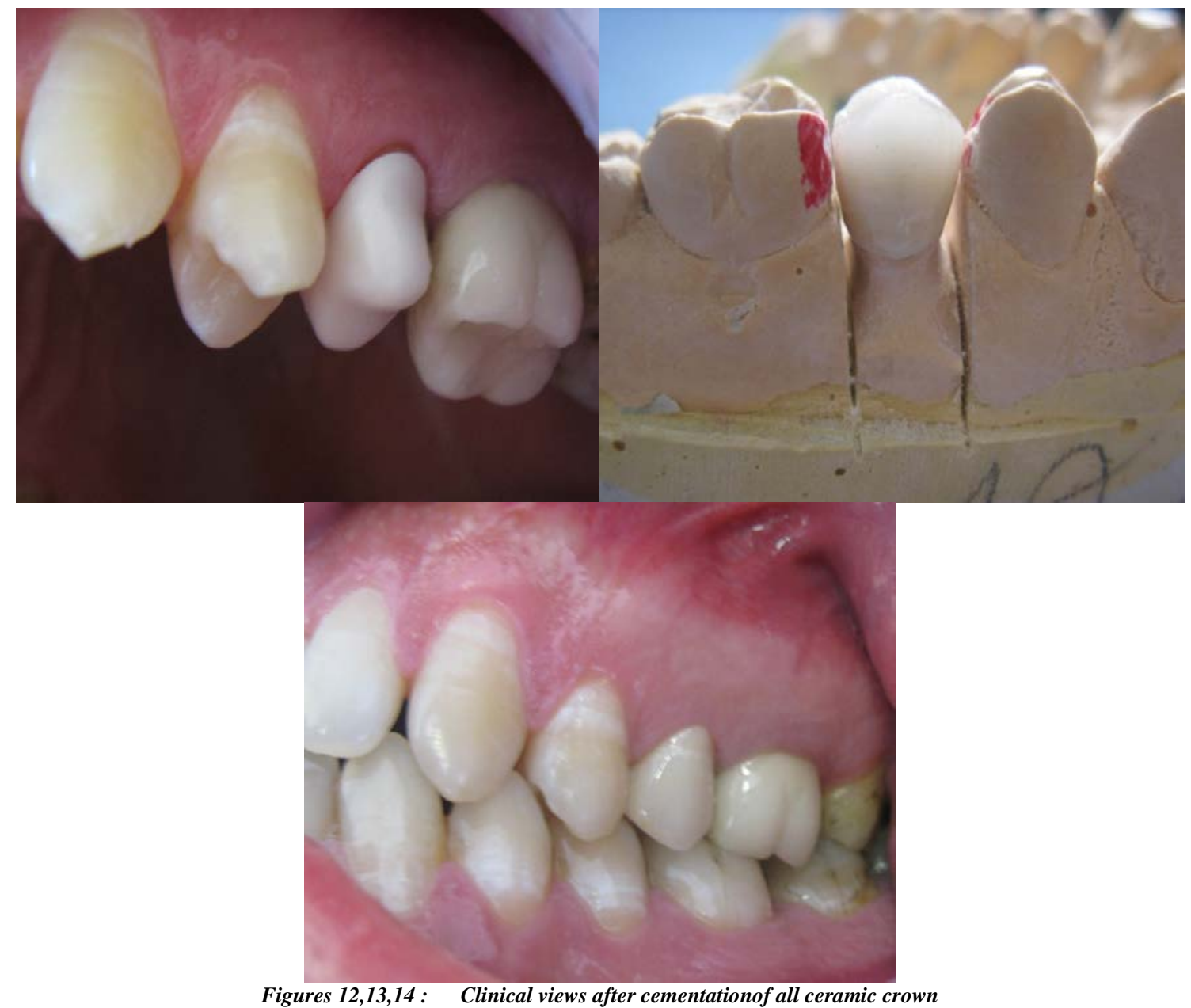

\section{DISCUSSION}

Fracture resistance is the most frequent failure mode of teeth restored using fiber posts. Longevity of treatment depends on several factors:

\section{Post length:}

Increasing the post length inside the root of endodontically treated premolar teeth restored with GFPs increase the fracture resistance to non-axial forces. Short GFPs seemed to adversely affect the fracture resistance of ETT (6).

\section{Number and location of posts:}

No significant difference was observed between the fracture resistance of endodontically treated maxillary first premolars restored with size 3 single post of longer length and size 1 double posts of shorter lengths. Thus, two shorter and thinner post scan be considered as an alternative to the use of a broader and longer post in teeth with shorter and curved root as well as to preserve more tooth structure (9).

Fiber post location has a significant effect on fracture resistance of severely damaged, endodontically treated maxillary premolars with two roots.

Post placement in the palatal root is preferred, as it maintains the restorability of the tooth (11).

\section{Remaining tooth structure:}

The remaining bulk of tooth structure plays a vital role in terms of strength and resistance to root fracture (9). It has been clearly shown that the survival rates of ETT are strongly related to the preservation of tooth structure. Regardless of the restorative procedure, the preservation of at least one coronal wall significantly reduced failure risk (12).

Mohamed Mohey Eldin Mohamed considered that under the limitation of his study, the thickness of remaining coronal 
dentin significantly affects the fracture resistance of endodontically treated teeth restored whatever by casted metal or fiber post and core(7).

Abutment height is another factor to consider, a number of studies recommended a minimal height of $2 \mathrm{~mm}$ of intact tooth structure above the crown margin for 360 degrees around the circumference of the tooth preparation as a rational guideline for the ferrule effect. Jie lin concluded in his study failure that mode is more favorable with reduced abutment height (6).

Fiber post and core $\mathrm{Vs} \mathrm{Ni}-\mathrm{Cr}$ post systems and zirconia post-and-core systems

Compared to zirconia post-and-core systems and cast Ni-Cr post systems, fiberglass posts with composite cores showed the highest fracture resistance values under allceramic crowns in endodontically treated premolars. (5)

\section{Fiber post and core composite restorations without any post}

Recently, an increasing number of papers have been advocating the use of direct composite restorations without any post for ETT. The greatest advantage of this " simplified » approach is that all the dental substrates remaining after caries removal and root canal treatment can be easily preserved This specific research issue still partially contoversial.

\section{CONCLUSION}

Fiber posts, used in combination with adhesive techniques, allow for the creation of a homogeneous and integrated unit, involving the restorative materials, the dental substrates, and all the interfaces.

Compared with the premolars restored with a metallic post, the fiber post generates lower stress along the interface and higher stresses in the root. However, with the fiber post, fracture is less likely to occur in the root since its core and post fracture indices are higher (1).

Preservation of sound coronal tooth structure and the presence of ferrule are important factors to decrease the wedging force of posts (7).

Abbreviations: ETT for endodontically treated teeth; GFPs for glass fiber posts

Conflict of Interests: Authors declare no conflict of interests

Acknowledgement: None

Source of Funding: None

\section{REFERENCES}

1. A.F.V. Santos, J.B.C. Meira, C.B. Tanaka, T.A. Xavier, R.Y. Ballester, R.G. Lima, C.S. Pfeifer, A. Versluis. Can Fiber Posts Increase Root Stresses and Reduce Fracture?

Journal of dental research, Volume: 89 issue: 6, page(s): 587-591

2. Atais Bacchi, Ricardo Armini Caldas, Daniel Schmidt, Mauricio Detoni, Matheus Albino Souza, Doglas Cecchin, and Ana Paula Farina. Fracture Strength and Stress Distribution in Premolars Restored with Cast Post-and-Cores or Glass-Fiber Posts Considering the Influence of Ferule. BioMed Research International ; Volume 2019

3. Nicola Scotti ; RiccardoRota ; MarcoScansetti; Davide Salvatore Paolino ; Giorgio Chiandussi ; Damiano Pasqualini ; Elio Berutti; Influence of adhesive techniques on fracture resistance of endodontically treated premolars with various residual wall thicknesses. Journal of prosthetic dentistry, volume 110 , issue 5, p 376382

4. J. Juloski, G.M. Fadda, F. Monticelli, M. Fajó-Pascual, C. Goracci, M. Ferrari. Four-year Survival of Endodontically Treated Premolars Restored with Fiber Posts. Journal of dental research. Volume: 93 issue: 7, page(s): 52S-58S

5. Habibzadeh S, Rajati HR, Hajmiragha $\mathrm{H}$, Esmailzadeh S, Kharazifard $\mathrm{M}$. Fracture resistances of zirconia, cast Ni$\mathrm{Cr}$, and fiber-glass composite posts 
under all-ceramic crowns in endodontically treated premolars. J Adv Prosthodont. 2017;9(3):170-175. doi:10.4047/jap.2017.9.3.170

6. Lin J, Matinlinna JP, Shinya A, Botelho MG, Zheng Z. Effect of fiber post length and abutment height on fracture resistance of endodontically treated premolars prepared for zirconia crowns. Odontology. 2018 Apr;106(2):215-222. doi: 10.1007/s10266-017-0320-7. Epub 2017 Dec 14. PMID: 29243185.

7. Mhamed Mohey Eldin Mohamed. The effect of remaining coronal dentin wall thickness on fracture resistance of endodontically treated teeth restored with post and core. Egyptian dental journal, Vol. 64, 3661:3671, October, 2018

8. Zarow M, Vadini M, Chojnacka-Brozek A, Szczeklik K, Milewski G, Biferi V, D'Arcangelo C, De Angelis F. Effect of Fiber Posts on Stress Distribution of Endodontically Treated Upper Premolars: Finite Element Analysis. Nanomaterials (Basel). 2020 Aug 29;10(9):1708. doi: 10.3390/nano10091708. PMID: $32872519 ;$ PMCID: PMC7559636.

9. Mayya A, Naik R, Mayya SS, Paul MP. Fracture Resistance of Endodontically Treated Maxillary Premolars with a Longer Single Post and Shorter Double Posts of Different Sizes: An In Vitro Study. J Int Soc Prev Community Dent. 2020;10(2):183-184. Published 2020 Apr 20. doi:10.4103/jispcd.JISPCD_472_19
10. Soares CJ, Soares PV, de Freitas SantosFilho PC, Castro CG, Magalhaes D, Versluis A. The influence of cavity design and glass fiber posts on biomechanical behavior of endodontically treated premolars. J Endod. 2008 Aug;34(8):1015-9. doi: 10.1016/j.joen.2008.05.017. PMID: 18634938.

11. Sulaiman E, Alarami N, Wong YI, Lee WH, Al-Haddad A. The effect of fiber post location on fracture resistance of endodontically treated maxillary premolars. Dent Med Probl. 2018 JulSep;55(3):275-279. doi: 10.17219/dmp/94656. PMID: 30328305.

12. Ferrari M, Vichi A, Fadda GM, Cagidiaco MC, Tay FR, Breschi L, Polimeni A, Goracci C. A randomized controlled trial of endodontically treated and restored premolars. J Dent Res. 2012 Jul;91(7 Suppl):72S-78S. doi: 10.1177/0022034512447949. PMID: 22699672.

13. Rodrigues RV, Sampaio CS, Pacheco RR, Pascon FM, Puppin-Rontani RM, Giannini M. Influence of adhesive cementation systems on the bond strength of relined fiber posts to root dentin. J Prosthet Dent. 2017 Oct;118(4):493-499. doi: 10.1016/j.prosdent.2017.01.006. Epub 2017 Mar 24. PMID: 28343677.

How to cite this article: Adli A; Gassara Y; N. Daouahi et.al. Endodontically treated maxillary premolars restored with glass fiber post under all ceramic crown. Int J Health Sci Res. 2021; 11(12):53-58. DOI: https://doi.org/10.52403/ ijhsr.20211208 